\title{
Are constructivist approaches in teaching health librarians effective? A reflective case study of teaching a course in health librarianship
}

\author{
Greg Rowell and Dean Giustini
}

\section{Introduction}

[In teaching student librarians]...there needs to be a fundamental shift from thinking about information resources and information literacy to a focus on knowledge construction and human understanding, implemented through a constructivist, inquiry based framework [1].

This paper examines the use of constructivist teaching in a course on health librarianship. Offered at the School of Library, Archival and Information Studies (SLAIS) at the University of British Columbia (UBC), LIBR534 is an introduction to health information sources and services [2]. Since the early 1960s, the course has been offered in alternate years and taught by one or two professional health librarians [3]. Its purpose has always been to provide an introduction to health librarianship and the major information sources in medicine and allied areas. As the field has evolved, the course has responded and integrated topics such as evidence-based practice, health informatics, and digital reference services [4].

For practical reasons, the instructors have been able to foster relationships with students participating in the student interest group (SIG) of the Canadian Health Libraries Association / Association des bibliothèques de la santé du Canada (CHLA / ABSC) at SLAIS. The SIG provides opportunities for those students who want to meet professional health librarians (many of whom are alumni of our class). Further, those who want to explore advanced studies can do so with the instructors or arrange a practicum with the Health Libraries Association of British Columbia (HLABC) member libraries [5].

In 2008, after teaching LIBR534 several times, we discerned a need to make some changes to didactic structure and delivery. In previous course evaluations, students had clearly expressed their desire to work together and to exam- ine information problems with their peers. We could see that SLAIS students were not unlike students in other professional programs in that they wanted more active, enquirybased learning experiences [6]. In planning for the 2008 offering, we restructured the course with this desire in mind.

In modifying the course, we envisioned a learning environment where knowledge-based and problem-based learning (PBL) would be used (see Appendix A). On the one hand, time to gain the basic knowledge of the field was important, but skills such as analysis, synthesis, and evaluation were also critical. A balance would need to be found between conveying concepts and promoting the interpersonal skills and behaviours associated with professional practice.

But with two pedagogical methods already in play, why introduce constructivist principles? "[I]n constructivism, students take responsibility for their own learning rather than relying on the teacher" $[7,8]$. We feel that this method was important for building autonomy in students. Even though adopting constructivist teaching can present a number of challenges for us as teachers, we felt ready to experiment.

We are now taking time, as reflective practitioners, to consider and review our teaching of LIBR534 in 2008 when we used constructivist methods [9]. Using a case format, we orient readers in this paper to setting, participants, and content, and share information from our students' evaluations. Throughout, we share our own informal observations about whether interactive, problem-based techniques were successful. We conclude by discussing our plans for LIBR534, next offered in January 2010.

\section{Methods}

In the fall of 2008, 28 Master of Library and Information Science (MLIS) students enrolled in LIBR534 - the largest cohort we had had to date. The course syllabus was posted on the UBC

G. Rowell. University of British Columbia Woodward Library \& Hospital Branch Libraries, 2198 Health Sciences Mall, Vancouver, BC V6T 1Z3, Canada; and School of Library, Archival and Information Studies (SLAIS), Irving K. Barber Learning Centre, University of British Columbia, 1961 East Mall, Vancouver, BC V6T 1Z1, Canada.

D. Giustini. ${ }^{1}$ Gordon and Leslie Diamond Health Care Centre, University of British Columbia, 2775 Laurel Street, Floor 2 , Vancouver, BC V5Z 1M9, Canada; and SLAIS, Irving K. Barber Learning Centre, University of British Columbia, 1961 East Mall, Vancouver, BC V6T 1Z1, Canada.

${ }^{1}$ Corresponding author (e-mail: dean.giustini@ubc.ca). 
Health Library Wiki (http://hlwiki.slais.ubc.ca/index.php? title=Instructors\%27_preparation_for_LIBR534). As an elective, the course had prerequisites but attracted students early in their LIS programs. To lead and facilitate learning, both instructors attended all classes, which were held on Tuesday nights from 6:00 to 9:00 PM.

To add variety to weekly classes, eight guest speakers were invited to share their views. Students were given two search assignments to complete independently (or with their peers). There were two group assignments; peer-review components were included in both. Different topics were presented each week, and readings were chosen to highlight important themes. Each class began with a short presentation. Mid-class, after a coffee break, students formed small groups so they could discuss the concepts, themes, or controversial issues arising from the readings.

We hoped our hybrid approach of constructivism and PBL would encourage students to be actively engaged in discussion and problem-solving. When appropriate, we shared our professional experience and encouraged students to do the same. With more content than time given the range of topics we had programmed (i.e., evidence-based practice, health informatics, consumer health issues, using Web 2.0 tools, etc.), we made four major changes to accommodate scheduled content:

(1) The sequencing of topics was altered

(2) A content management system was used to encourage online discussion and exchange of information between weekly classes

(3) Class discussions put students in small groups to analyze readings and cases

(4) Course assignments and participation incorporated selfreflection and peer review

\section{Results}

\section{Student reflections}

The analysis of our course evaluations is a critical step in reflective practice and for our planning of subsequent offerings of the course. In reviewing the evaluations several key themes emerged: student frustration with time and insecurities about the subject matter, the effectiveness of guest speakers, the challenges of group dynamics, the use of the constructivist model as the underlying pedagogy for the course, and comments about the instructors and the course as a whole.

Some students expressed being intimidated by the subject matter. Students expressed frustration about unfamiliar biomedical terms; students with health sciences knowledge seemed to increase anxiety levels in the class as a whole given their ease with advanced scientific concepts.

The students responded well to guest speakers. Their comments clearly indicated our guest speakers' added value in providing interesting perspectives on a variety of topics. We were proud to invite students from previous years (who now work in health libraries) to talk about their work.

Even though we believed that the quality of student assignments was high, some students actually noted that the range of marks from low to high was not widely spread. In an elective, it is easy to skew marks to a high median, and we may have been too lenient in our marking.

In the group papers, a range of effective and collegial teamwork was observed, but some problems did arise. Some students did not do their fair share of the work - a perennial problem. Complaints arose from within some groups about students completing work that did not meet class standards.

We were pleased with the level of student participation and the willingness to engage in group work (marks for participation $=20 \%)$. It was critical that each student identified the best (and most comfortable) way to participate. Some students cited weekly classes as critical to their participation but said they did not feel it necessary to contribute to online discussions. Giving students options seemed to keep them happy.

Generally, students viewed our move to a constructivist model favourably. The following is a selection of student comments taken from the fall 2008 course evaluations:

This was a very "constructivist" course where we were allowed and encouraged to learn on our own through discussion and experience. I generally liked this approach but a bit more lecture-style structure would have given more weight to the theoretical concepts.

I think that Vista blackboard is a place to "post ideas" but does not foster discussion. So instructors need to make good use of the class time to let students discuss topics together with instructors facilitating but not dominating the discussions.

A third practical assignment could have been added and less emphasis could have been placed on online discussion.

There was too much emphasis on self/peer evaluation. Although this may have been appropriate for one small exercise/assignment it does not seem appropriate to use this form of evaluation for $25-30 \%$ of the final marks. Even though professors can override marks, they may choose not to. Many factors come into the process of self/peer evaluation that make it far too subjective, especially for students, of which there was a majority, who have no experience with this process.

Making students feel valued as learners is an important part of building relationships; we were pleased to see that students recognized and mentioned this in their evaluations. Some students had suggestions for improving the way we teach: "one instructor would be better if he didn't mumble" or "one instructor would be better if he didn't cut the other instructor off". A few students commented that our expectations were sometimes unclear despite detailed instructions we made available at the beginning of term.

Overall most of our students' comments indicated that they seemed to enjoy the interactive teaching we used and the humorous, collegial approach we brought to debate. Our students rated both the course content and the teaching of it highly.

\section{Discussion}

In looking back at this iteration of the course (and student reactions to it), several issues come to mind. We believe the course was significantly impacted by our decision to move 
to constructivist principles; by extension, changes to the scope of the course, our online interactions with and between students, and how we evaluated them created quite a different learning environment. While there is room for finetuning many aspects of this approach, we believe that the overall usefulness of the course remains uncompromised.

\section{Instructor reflections}

Teaching is a labour of love; despite its many challenges, we enjoy teaching student librarians and giving back to our profession. That said, as health librarians who instruct users to search the literature efficiently [10], we feel that we are still novices at teaching at the graduate level. As Canadian academic health librarians teaching in an American Library Association accredited program, we feel challenged beyond our academic preparation and beyond anything that we have encountered as practitioners. The demands of teaching a 13week course for 3 hours per week exceed most of what we regularly encounter in teaching information literacy.

However, we derive much satisfaction from graduate students and the challenges of teaching at this level. When we began teaching several years ago, we delivered content in the way we were taught: by lecturing to our students. "Sage on the stage" or behavioural models place instructors as authority figures in class; they impart the content and control information flow [11]. Behaviourism has long been the dominant teaching model and is just now being replaced in higher education by student-centred pedagogies [12].

The move to problem-based learning (PBL), applied with success in other health programs, offered real potential for restructuring how we taught the course. We were aware that PBL had been used since the 1970s and was seen as the sine qua non in medicine, engineering, and education [13]. The evidence of using PBL was scant in the library and information science literature $[14,15]$, but as methods go, it presented us with a number of attractive options to help our students learn more deeply and efficiently. These changes in delivery brought our course into alignment with other health-related classes. Medical education, for example, has moved away from passive learning and rote memorization to emphasizing information synthesis, problem solving, and working in teams. So why wouldn't this work for health librarians? With revision (e.g., building a database of interesting health science library scenarios) we think this will be an effective strategy for this course.

In preparing to teach this class, we felt that monitoring student progress would be easier than it turned out to be. We had contemplated making changes "on the fly" during the term, but this was not feasible given the demands of fulltime jobs. When we lost our way, we returned to the goals and objectives articulated for the class, which had the effect of reorienting us. In future we need to revise our methodology to manage this process more effectively.

Health librarianship is a profession rooted in traditions that date back to the 19 th century [16]. But these traditions must be recontextualized for today's health care environments. Occasionally, with so much to learn and absorb, it seemed as though the lack of time rushed students; they then became frustrated in their attempts to learn the material. Consequently, were we being too ambitious? Were we presenting a coherent view of health librarianship? Was a better balance to be found by emphasizing evidence-based practice and expert searching? Could newer information technologies such as social media be left out?

Incorporating online collaboration mechanisms was essential. The UBC Health Library wiki was a great platform although spam problems did create some difficulties. Discussions on Blackboard threatened to be disjointed, but students used it to write reflections on their classroom experiences, while others took advantage of in-class debate to express themselves. We need to find a way find a way to accommodate all manner of student reflection.

The way the course progressed generated some angst for us. We contemplated whether our students would be overwhelmed with information. We continually seemed to be adjusting to the fact that we were facilitating, not teaching, per se. For constructivism to be successful, we know, learners must learn to solve problems on their own. It was difficult not to offer specific solutions for problems our students seemed to be having. We also had minor administrative difficulties in keeping track of students' self assessments and of their group members.

However, evidence of our success came in the way of comments such as the following:

\begin{abstract}
Among the practical things I learned about search MEDLINE and using online sources, what stands out for me as a student in this class was how valued I felt. You and Greg showed such respect for us as students and understanding as we made attempts to learn the content. In a small way I think you helped me change my perspective on my ability to learn. Thank you.
\end{abstract}

\section{Curriculum plans for 2010}

Reflective practices can often peel back layers of the educational process that are not always easy to reverse. Having done so, however, what seems clear is that LIBR534 needs major revisions before we can offer it again at SLAIS. More teacher-guided instruction, for example, will need to be integrated into the 2010 offering. We will need to do this at the start of term so students become more familiar with basic vocabulary and terminologies used in health libraries. It might be worthwhile to place students with similar skill levels together in small groups so the more knowledgeable students do not dominate.

In the course evaluations, students said they wanted to spend more time on the fundamentals of biomedical searching and more on information retrieval to support clinical research. As searching the medical literature is an important part of our future as health librarians, we will certainly find time to program more search classes. Even though the inclusion of social media topics was well received, some students expressed more interest in hearing about advanced reference and collections management. Since the Winter Olympics will be held in Vancouver during the time we are teaching, we will seek out ways to introduce sports-related searching and sports medicine into the curriculum.

\section{Conclusion}

The use of constructivist approaches in teaching a health librarianship course has proven to be successful. The in- 
structors feel that their post hoc evaluations (and this case study) have necessitated some major changes before the course can be offered in January 2010.

One of the residual benefits of using PBL is that students and instructors begin to understand how their future users (i.e., health professionals) meet over cases. With respect to the fit of PBL and LIS education, using constructivist methods presents several challenges: for example, facilitating student librarians to find their own answers can take up more class time than is available; students with pre-existing knowledge can create power imbalances in groups, and it may be better for them to pursue directed study work with one of the instructors than take LIBR534; and peer assessment created some interpersonal difficulties and an instance of student conflict. These components need to be reexamined and suitable alternatives found.

We conclude that our teaching partnership remains strong and resistant to most challenges in LIBR534. Clearly, changes to content or delivery method will not interfere with our ability to create a good learning environment for our students. The mutual respect we have for each other - as well as our ability to laugh at our own (and each other's) foibles conveys something to students well beyond our ability to teach them specific on-the-job skills.

\section{References}

1. Todd RJ. Learning in the information age school: opportunities, outcomes, and options. In: International Association of School Librarianship Conference; 2003 Jul 7-11; Durbin, South Africa. Available from: http://www.iasl-online.org/ events/conf/conference2003-virtualpap.html.

2. School of Library, Archival and Information Studies. LIBR534 Health Information Sources and Services syllabus. Available from: http://www.slais.ubc.ca/COURSES/coursdes/libr/libr534.htm.

3. Henderson J. Colin William (Bill) Fraser, AHIP, FMLA, 1925-2005. J Med Libr Assoc. 2006 Apr;94(2):240-41.

4. UBC Health Library wiki. LIBR534: Health Information Sources and Services. Available from: http://hlwiki.slais.ubc.ca/index. php/LIBR_534:_Health_Information_Sources_and_Services.

5. Giustini D, Hooker D, Li X, Bradley S. Bridging a gap between MLIS students at UBC and health librarians: a case report from 2006-2010. In: CHLA / ABSC Annual Conference; 2009 May 30 - Jun 3; Winnipeg, Manitoba.

6. Warhurst RP. "We really felt part of something": participatory learning among peers within a university teachingdevelopment community of practice. Int $J$ Acad Dev. 2006;11(2):111-22.

7. Giustini D. Part I. Utilizing learning theories in the digital age: an introduction for health librarians. J Can Health Libr Assoc. 2008 Sep;29:109-15.

8. Tynjala P. Towards expert knowledge? A comparison between a constructivist and a traditional learning environment in the university. Int J Educ Res. 1999;31(5):357-442.

9. Rowell G, Giustini D. Are constructivist approaches used to teach health librarians effective? A case-study on teaching a course on health librarianship. In: CHLA / ABSC Annual Conference; 2009 May 30 - Jun 3; Winnipeg, Manitoba.
10. Tuttle BD, von Isenburg M, Schardt C, Powers A. PubMed instruction for medical students: searching for a better way. Med Ref Serv Q. 2009;28(3):199-210.

11. Bednar AK, Cunningham D, Duffy TM, Perry JP. Theory into practice: How do we link? In: Anglin GJ, editor. Instructional technology: Past, present and future. Englewood, (CO): Libraries Unlimited, Inc.; 1995.

12. Akinou O, Tandoan RO. The effects of problem-based active learning in science education on students academic achievement, attitude and concept learning. Eurasia J Math Sci Technol Edu. 2007;3(1):71-81.

13. Barell J. Problem-based learning: an inquiry approach. Thousand Oaks, (CA): Corwin Press; 2007.

14. Dimitroff A, Ancona A, Beman SB, Dodge AM. Problembased learning in a health sciences librarianship course. Bull Med Libr Assoc. 1998 Jul;86(3):340-45.

15. Yukawa J. Factors influencing online communication style in LIS problem-based learning. J Ed Libr Info Sci. 2007;48(1):52-63.

16. Connor J. Guardians of medical knowledge: the genesis of the Medical Library Association. Lanham, (MD): Medical Library Association and Scarecrow Press; 2000.

\section{Appendix A. Glossary}

Behaviourism - is best described as "observable, testable and verifiable behaviours" in learners. The predominant learning theory of the 20th century, it positions teachers as vessels of knowledge ("sage-on-the-stage") authority figures where the "truth" (stimulus) is literally downloaded into learners. Later, their recall (response) of facts was tested and rewarded (or punished) accordingly (i.e., think of Pavlov's experiments with his dog).

Constructivism - puts the onus on individual learners to actively construct new knowledge by responding to new ideas, people, and situations and by reflecting on their experiences.

Knowledge-based learning — for our purposes here, simply basing the learning environment on the subject domain (or knowledge-base) of health librarianship, its parameters, information sources, databases, principles, facts and figures, etc.

Problem-based learning $(P B L)$ - drawing on enquirybased as well as constructivist methods of learning, PBL is situated around the discussion of concepts in the form of cases. Learners all take responsibility for participating and in arriving at suitable and realistic solutions for complex problems.

Reflective practice - is linked to constructivism in that learners carefully consider, through reflection, what they know and what they don't know. It is thought that reflective practices encourage the pursuit of information and its assimilation to make sense of the world. 


\section{Appendix B. Course evaluation questions}

Term 12008 Faculty Evaluation Questionnaire University of British Columbia SLAIS Instructors Course: LIBR534 001 - Health Information Sources and Services

Students were asked to base their answers to the following statements by using a 5-point scale $(1=$ Strongly disagree, $2=$ Disagree, $3=$ Neutral, $4=$ Agree, and $5=$ Strongly agree). These numbers were then tabulated and a mean average was given for each. When the instructors received these evaluations, they were also given a median for all courses taught by faculty and adjuncts.

\section{Arts course evaluation}

(1) Evaluation procedures were fair and reasonable.

(2) The course was well organized.

(3) The course requirements were clearly outlined to students.

(4) How would you rate the contribution of the textbook(s) and (or) assigned readings or media to the course?

(5) Considering everything, how would you rate this course?

(6) Please comment on any aspects, positive or negative, of the format and content of the course.

\section{University module}

(1) The instructor made it clear what students were expected to learn.

(2) The instructor communicated the subject matter effectively.

(3) The instructor helped inspire interest in learning the subject matter.

(4) Overall, evaluation of student learning (through exams, essays, presentations, etc.) was fair.

(5) The instructor showed concern for student learning.
(6) Overall, the instructor was an effective teacher.

\section{Arts instructor questions}

(7) In classes where the size of the class and content of the course were appropriate, student participation was encouraged by the instructor.

(8) High standards of achievement were set.

(9) Intelligent and independent thought by students was encouraged.

(10) The instructor was helpful when the students requested course related assistance outside of class.

(11) The instructor was generally well prepared for class.

(12) The instructor was readily available to students either through regular office hours or by appointment.

(13) The instructor communicated at an appropriate level for the class.

(14) The instructor was articulate and communicated effectively.

(15) The instructor attempted to answer all questions in class to the best of his or her ability.

(16) The instructor established good rapport with students in the classroom.

(17) The instructor demonstrated thorough knowledge of the subject.

(18) As a result of the instructor's effort, you became more interested in the subject.

(19) The instructor communicated interest in the subject matter.

(20) Assignments and tests were returned within a reasonable time.

(21) The instructor treated you and other students with equal respect.

(22) Considering everything, how would you rate your instructor?

(23) Please comment on any aspects, positive or negative, of your instructor's teaching, attitudes to students, class atmosphere, or any other matters affecting the quality of instruction that you consider worthy of note. 
This article has been cited by:

1. MaL.. 2010. Musings of a student librarian: a case report of taking a course in health librarianship. Journal of the Canadian Health Libraries Association 31:3, 95-98. [Abstract] [PDF] [PDF Plus] 